\title{
Commissioning of a High Speed Composite Rotor with Hydrostatic Dampers and Ceramic Rolling Element Bearings
}

By:

R.N. Headifen

R.L. Fuller

J.R. Kitzmiller

14th ASME Vibration and Noise Conference, Albuquerque, NM September 19-23, 1993.

PR - 182

Center for Electromechanics

The University of Texas at Austin

BRC, Mail Code 77000

Austin, TX 78712

(512) 471-4496 


\title{
COMMISSIONING OF A HIGH SPEED COMPOSITE ROTOR WITH HYDROSTATIC DAMPERS AND CERAMIC ROLLING ELEMENT BEARINGS
}

\author{
Ross N. Headifen, Robert L. Fuller, Jon R. Kitzmiller \\ Center for Electromechanics \\ The University of Texas at Austin \\ Austin, Texas
}

\begin{abstract}
A high speed $(25,000 \mathrm{rpm})$ rotating machine with a $300 \mathrm{lb}$ rotor was designed and manufactured. To accommodate the high shaft speed, 2.6 million DN, rolling element bearings were used with ceramic balls and inner races. In order to control the magnitude of the vibration, damping was incorporated into the system using nonrotating hydrostatic dampers. The journal for the dampers was a cylindrical cartridge that had the rolling element bearings clamped inside of it. Extensive analysis was performed on this system. A computer program was written that could model the orbit path of the lumped mass shaft in the damper over the full speed range. A second program was also written that calculated the damper nonlinear stiffness and damping coefficients, and incorporated them in with a one-dimensional beam, finite element rotordynamics model of the system. Analysis results are presented along with experimental run data from the machine. Balancing problems encountered during commissioning have limited the results to $16,500 \mathrm{rpm}$ to date. The last of which is currently being remedied.
\end{abstract}

\section{INTRODUCTION}

A pulsed electric generator called a compensated pulsed alternator, (compulsator) (Weldon, 1980) was designed, built, and tested for use as a pulse power supply. The first generation of these new type of machines was a relatively low-speed, iron-core, low energy density machine manufactured primarily of commonly available materials. The third generation of this type of alternator is the subject of this paper. This new compulsator has an air-core rotor, and is manufactured with a ceramic shaft and composite materials. The typical mode of operation for the compulsator is to spin up the rotor to speed, charge the field coil, and close a switch; discharging the compulsator in a succession of three 385,000 A bursts. After the discharge, the rotor is brought to rest, the whole cycle lasting less than five minutes. The design speed for this machine is $25,000 \mathrm{rpm}$ $(520 \mathrm{~m} / \mathrm{s} \mathrm{tip} \mathrm{speed)} \mathrm{where} \mathrm{the} \mathrm{rotor} \mathrm{stores} 8.8 \mathrm{MJ}$. The rotor has three sets of bearings: two main bearings which support the rotor, and a third bearing which supports the brush gear extension shaft. The bearing system selected for the compulsator was rolling element bearings (REBs) due to their low auxiliary requirements. The presence of magnetic fields at the bearing locations precluded any rotating metallic components. For this reason and due to the high speed of 2.6 million DN (product of shaft diameter in $\mathrm{mm}$ and rpm), hybrid ceramic rolling element bearings were selected. These bearings have a ceramic inner race, ceramic balls and rollers, a silverplated bronze retainer, and a steel outer race. Initially, rigid bearing supports were proposed. This resulted in a bending mode shape for the first rotor critical frequency. It is desirable for this machine to have the first critical speed be at least $30 \%$ above the peak operating speed. This will limit the displacement magnification ratio to 1.45 (Vance, 1988). However, detailed modeling of the shaft/rotor including pseudo, three-dimensional, finite element modeling, showed that this margin was not possible, and a more realistic critical speed was only $10 \%$ over the peak operating speed. With no damping in the system, this would have resulted in excessive machine vibration.

Damping was incorporated into the machine, via nonrotating hydrostatic damper bearings around the REBs. The authors had considerable experience with pure hydrostatic bearings on other machines (Headifen, 1991 and Kitzmiller, 1988). Choy (1981) showed that the forces on rolling element bearings could be significantly reduced if hydrostatic dampers were used in series with the ball bearings. Gunter (1970) described other cases that have been performed in which the low stiffness dampers were utilized whereby the first two critical speeds became rigid body modes, occurred at low speeds, and were primarily governed by the damper stiffness. 
The third or flexible critical speed nearly corresponds with the freefree mode and occurs at a much higher frequency than with the rigid mounts. He then presented an analysis for a rigid rotor with rolling element bearings mounted in hydrodynamic squeeze film dampers. Modeling of this type of arrangement for the compulsator showed significantly improved behavior over the rigid supports.

The outer race of the REBs for the compulsator are axially clamped inside a cartridge, the outer diameter of which serves as the journal for the hydrostatic damper. Figure 1 shows a drawing of the arrangement of the REBs mounted inside the damper sleeves. This is the thrust end of the system and the thrust runner plate can be seen as well as the radial damper. Like the radial dampers, the thrust runner is nonrotating but serves as a damper for axial motions. To get the maximum effect from the dampers, their stiffness has to be significantly less than the rolling element/shaft stiffness. This allows virtually all of the vibration amplitudes to occur in the dampers, providing maximum attenuation. The stiffness of a duplex set of the rolling element bearings was approximately 5.5 million lb/ in. Using a damper stiffness of approximately one order less in magnitude, means that the stiffness of the REBs/shaft has only a small effect on the dynamic analysis.

\section{ROTOR DYNAMIC ANALYSIS}

The aspect ratio of the rotor is approximately $1: 1$ and the stub shafts are made of a high modulus ceramic. These two factors mean that the rotor behaves as a rigid body. Hence, initial modeling of the system was performed with a hydrostatic bearing orbit simulation program (Headifen, 1991) and a linear finite element rotordynamics program (Manifold, 1979). The bearing program has the capability of turning the shaft spin on or off, allowing it to model a conventional hydrostatic bearing or a hydrostatic damper. The eight stiffness and damping coefficients can also be calculated at any eccentricity or specified load. The coefficients are calculated using the small displacements method. At high speeds, the effect of fluid compressibility can be significant, hence, the effect of compressibility is included. A new method was developed by the author and is described in reference (Headifen, 1991). Due to the thin film on the lands, the compressibility effect over the lands is small compared to the pocket compressibility. Hence, only the compressibility in the pockets was included. The program can also perform transient response and frequency response with the excitation function being a rotating imbalance.

The initial machine design was done without the hydrostatic dampers. This constrained the maximum diameter of the dampers which could be implemented and the lubricant viscosity. Due to details in the original design the REB lubricant had to be used for the hydrostatic damper fluid. The lubricant used is equivalent to ISO VG2. This is an extremely low viscosity oil that the REBs require to avoid excessive heat generation due to drag at high speeds. The supply pressure of $350 \mathrm{psi}$ is also fixed within limits as the same supply pumps are used for both the REBs and the hydrostatic dampers. Space considerations require the use of orifice jets as the method of compensation. The remaining variables are the bearing length, land widths, orifice size and clearance. The size of the orifice was kept small to reduce the flow rate into the damper pockets. The final damper design parameters are listed in appendix A.

The mass of the rotor is approximately $300 \mathrm{lb}$, with a damper stiffness of 0.5 to 0.75 million $\mathrm{lb} /$ in. at each end. This allows the level of critical damping to vary between 900 to $1,530 \mathrm{lb}$ s/in. at each end. The damper design was selected so that the level of damping was close to or less than the critical damping given the geometry constraints The damper design was an iterative process, in which the response and stability of the damper was determined over the full speed range.

The stiffness and damping coefficients for the main dampers are presented in figures 2 through 4 . There are no values for the cross coupled damping coefficients as these terms are approximately zero. Figures 5 and 6 show the orbits at 10,000 and $25,000 \mathrm{rpm}$. For these plots, the imbalance was adjusted so the imbalance force did not exceed $800 \mathrm{lb}$ for the bearing. Each plot shows an initial starting point followed by a steady state orbit. Phase markers are also shown. At approximately $10,000 \mathrm{rpm}$, the phase marker is at $90^{\circ}$ indicating that the rotor is at a critical speed. This is a cylindrical mode critical speed. Figure 7 shows the $25,000 \mathrm{rpm}$ case with the effect of compressibility included. There is no significant difference in the orbit plots indicating compressibility has little effect at these speeds. Figure 8 shows the same 25,000 rpm case but with the shaft spinning as in a conventional bearing. Now the orbit path shows an unstable response. The program attempts to find a starting point close to the orbit path for the steady state speed. For certain situations it does not converge to a position, hence the unusual initial value in figure 7 .

The next stage in the analysis was to change from the end-on view, lumped mass analysis performed by the bearing program to a side-on view one dimensional and pseudo three dimensional finite element analysis of the rotor system. This second analysis included all three hydrostatic dampers, the different material properties and geometry of each rotor section. This type of analysis allows parametric studies to be performed for imbalance size and location. The presence of the second rigid body critical speed and the effect of the shaft extension needed to be determined. Eigenvalue analysis shows that with rigid bearing supports, the first critical speed is a flexible mode at approximately $28,000 \mathrm{rpm}$. When the damper is included, using the concentric damper stiffness and damping coefficients in series with the ball bearing stiffness, the first two eigenvalues are rigid body modes at $10,000 \mathrm{rpm}$ and $18,000 \mathrm{rpm}$. The third rotor mode which is the flexible mode, rose to approximately 60,000 rpm. The actual third system mode, is a mode involving motion of the shaft extension in the third damper. It is at $34,500 \mathrm{rpm}$. Figure 9 shows centerline drawings of the mode shapes for these first two eigenvalues. Since these are damped mode shapes, they are represented in the complex plane. The plots show the real and complex components of the mode shapes. Extra nodes are included at the location of the damper joumals. Between the extra nodes and the rotor nodes are the REB stiffnesses. Between the extra nodes and ground are the damper stiffness and damping coefficients. The complex eigenvalue is printed under the title.

\section{ROTOR COMMISSIONING}

The rotor was initially two-plane balanced in a balancing machine at a low speed of $1,000 \mathrm{rpm}$. The method used was a 
standard four-run method with trial weights. Since the rotor is made from composite material, balancing was achieved with small tungsten pins imbedded into a balance ring. In the machine, vibration is monitored with velocity transducers attached to the stator and Bentley Nevada 3000 series probes with a BN DVF3 monitoring unit, measuring the gap between the rotor and stator. Two sets of orthogonal probes were used, one at each mainbearing location. A third pair was installed at the third bearing after run number 79. As well as the DVF3 unit, data was also collected at $4 \mathrm{~Hz}$ over the entire run and at $1,000 \mathrm{~Hz}$ for $2 \mathrm{~s}$ starting at the time of machine discharge. Space to position the BN probes was very tight, and consequently the targets used were not optimum. The targets had small discreet geometric variations such that the DVF3 unit was not able to correctly simulate the slow roll vector The consequence of this was that while the data measured with these probes was acceptable, determination of the null vector was inadequate and could not be used.

Commissioning of the machine was planned in phases. At each phase, a higher speed was to be attained. During each phase, numerous runs were made. Some of which were to characterize the rotor and machine vibration while others were used to perform checks and testing of the electrical circuits and controls and then to perform low energy discharges. Table 1 presents a summary of the run number and the speed reached at that time.

\section{TABLE 1. ROTOR SPEED AT COMMISSIONING RUN} NUMBER

\begin{tabular}{|c|c|}
\hline Run Number & $\begin{array}{c}\text { Speed } \\
\text { (rpm) }\end{array}$ \\
\hline 17 & 8,000 \\
\hline 26 & 10,000 \\
\hline 44 & 12,000 \\
\hline 68 & 14,500 \\
\hline 75 & 16,200 \\
\hline 85 & 16,500 \\
\hline
\end{tabular}

During the runs to $12,000 \mathrm{rpm}$, a resonant rotor vibration peak was observed at $11,300 \mathrm{rpm}$. This was the $10,500 \mathrm{rpm}$ critical predicted above. Here the peak to peak (p-p) vibration at the nonthrust end (NTE) was 2.2 mil. At this level of vibration, the peak velocity is $1.3 \mathrm{in} . / \mathrm{s}$ and the rotor was experiencing 4 gees of acceleration. There after, the p-p vibration dropped off to lower levels. While this level is in the rough range in the operating charts presented by Jackson (1979) it was decided to proceed with further runs. Also during these runs, other modes were detected by the velocity transducers at around $5000 \mathrm{rpm}$. They were picking up machine vibrations on the mounting skid. At this time these were not considered important.
During run numbers 70 to 78 , the vibration monitors at both ends indicated that the rotor was becoming unbalanced at the higher speeds. On run number 75 , the p-p vibration at the NTE was $3.2 \mathrm{mil}$ at $11,300 \mathrm{rpm}$ and on run number 78 , the p-p vibration was $4.2 \mathrm{mil}$. For run 78, this was a velocity of $2.5 \mathrm{in} . / \mathrm{s}$ and an acceleration of 7.6 gees. Figure 12 shows a plot of the rotor speed and the vibration for the horizontal and vertical planes at both ends for this run. The vibration is raw data and needs the mechanical runout of $3.5 \mathrm{mil}$ subtracted from it. This increase was not unexpected, considering the composite materials use in the manufacture of the rotor. It was thought that there would be some initial settling in period. These levels were considered too high to continue with the planned program, and the rotor was removed and rebalanced. Approximately $6 \mathrm{~g}$ was added to the thrust end (TE) and $7 \mathrm{~g}$ added to the NTE end to rebalance. These weights were added close to $180^{\circ}$ away from the initial balance weights, implying that there had been some physical movement within the rotor. Run number 85 was an attempt at 18,000 $\mathrm{rpm}$, but at $16,500 \mathrm{rpm}$ the vibration monitors tripped out at $4.5 \mathrm{mil}$ p-p. At this speed, this is $3.9 \mathrm{in} . / \mathrm{s}$ and 17.4 gees. Also for the ceramic bearings, this was a DN of 1.73 million. Figure 11 shows plots of the motion at the both ends of the stator. These were considered excessive conditions and the rotor was removed and the balance rechecked. Similar weights were again required, but this time approximately $180^{\circ}$ out from the previous balance. Initially, a poor balance job was suspected on the second balance job. The dampers were inspected for rubbing or wear however none was observed. Considering the forces they had experienced, this implied they were performing very well and had limited the forces experienced by the ceramic bearings. The trip limits were set at a lower p-p level of 3.5 mil. Run number 87 tripped out at $15,500 \mathrm{rpm}$. This lead to the suspicion that there was some other factor other than imbalance contributing to the runout problem. Under the direction of Dr. Vance, a renowned rotor dynamicist from Texas A\&M University, a waterfall plot was made for a 14,000-rpm run. This plot showed no subsynchronous whirling velocities or instabilities indicating that the rotor was balanceable.

Several attempts at in-situ balance were attempted without improvement. There appeared to be a significant interaction between rotor motion and motion of the machine on its tie down skid and phase interpretation was difficult to ascertain. A full modal analysis with an impact hammer and accelerometers was then performed on the skid and it was found that there were several lateral modes with low dynamic stiffness at 90,150 , and $260 \mathrm{HZ}(5,400$, 9,000 and $15,600 \mathrm{rpm}$ ) between the machine and skid it was mounted on. Figure 12 shows a plot of the dynamic stiffness results The skid was made from aluminum channel beams. A steel skid was not permitted due to its interaction with the magnetic field. A four inch thick aluminum slab was bolted in place as a temporary substitute tie down skid. Modal analysis showed this had removed all the foundation modes from the system.

Further balancing of the rotor was attempted. The balance method assumes a linear response of the rotor. However, these trials showed nonlinear corrections implying that the rotor could still not be balanced at this stage, indicating that there was some other factor involved. A dynamic signal analyzer with probes on the stator was used to monitor the vibration and compare with the proximitor probes. It was noticed there was a vibration frequency at twice 
operating frequency. Plots of this are shown in figure 13. The first shows the output from the BN proximitor probes fed into the spectrum analyzer. In this plot, the first peak is the $60 \mathrm{~Hz}$ noise, the second is the operating speed of $10,000 \mathrm{rpm}$, and the third is the two times frequency. The second figure is from accelerometers which shows the two times frequency to be more pronounced than the proximitor probes show. Vance (1988) describes the appearance of a two times speed frequency as being attributed to a bearing misalignment. Ithad previously been noticed that the housing extension the third outer bearing was mounted in was the least stiff part of the stator and lateral motions of this housing had been detected. Originally, a lightweight third mount had been used to support this extension. This had been replaced with a significantly stiffer one early on. Based on the bearing misalignment theory, the alignment of the dampers was rechecked. A 0.007 in. misalignment was discovered at this third damper location. The damper housing was removed and reinstalled in the aligned position. At the same time, a check of the connection that connected the shaft extension for the slip rings to the main ceramic shaft was made. This had been designed as a rigid coupling; however, performing load tests showed that it was not rigid and would take a small permanent offset in the direction of the load. The consequences of this was that the shaft would always be misaligned as the rotor whirled around. A redesign of the connection was performed and implemented. Further load tests showed that new design was rigid and the offset no longer occurred.

Subsequent balance runs were made with trial weights at the outer end of the extension shaft to determine their influence on the rotor behavior. A strong influence between these weights and the rotor motion was observed. This led to a three plane balance procedure being tried. Results of balancing with this procedure at $11,000 \mathrm{rpm}$ showed that the rotor was well balanced. However, starting at approximately 13,000 , the rotor vibration would rapidly increase with the appearance of a low damped system. Examination of the pocket pressure in the dampers showed it was possible that cavitation was occurring due to the low viscosity oil with a low flash point. The next higher viscosity oil ISO VG6 was substituted to provide higher pocket pressures. The response showed little difference overall, indicating the dampers had not been cavitating. At about the same time however, another anomaly was observed. The rotor would initially spin up to $11,000 \mathrm{rpm}$ with slight observable vibration, then after a few minutes the vibration would suddenly disappear and a very smooth response occur. Initially, this was thought to be due to thermal changes in the system. Test runs were begun to find the cause of this effect. After six runs with this behavior, the machine was reexamined and a broken ceramic spacer in between the two REBs on the thrust end was discovered. The machine was disassembled and the rotor joumals and other bearings visually inspected. The titanium journal on the thrust end had been severely gouged by ceramic fragments and needed replacing. The ceramic bearing set appeared not to be damaged but it was replaced with a new bearing set as a precaution. At the time of writing this paper, new titanium journals were being machined and installed. The ceramic spacers in the bearings were also being replaced with titanium spacers. Commissioning will continue after these modifications.

\section{CONCLUSIONS}

A high speed rotating machine was designed and built. The three bearing system used ceramic rolling element bearings in series with hydrostatic dampers to limit machine vibration. The inclusion of the low stiffness dampers pushed the flexible critical speed to a very high frequency and introduced two rigid body modes at frequencies below peak design speed. During commissioning of the machine, excessive rotor vibration occurred at $16,000 \mathrm{rpm}$. At this speed, the rotor had a linear velocity of $3.9 \mathrm{in} . / \mathrm{s}$ and was experiencing 17.4 gees. These are high numbers; however, due to the dampers, no problems were caused at these levels, thereby concluding that the dampers were attenuating significant forces and protecting the ceramic bearings. At this speed, the DN value for the ceramic bearings is 1.73 million. The high vibration was determined to be due to several factors. A low stiffness tiedown skid added to the vibration and masked the true phase relationship so that position of balance weights could not be accurately determined. A bearing misalignment in the third bearing was discovered by observing a two times, running speed frequency. Also, even though the mass of the brushgear extension shaft was small compared to the rotor mass, it was also determined that a three-plane balance was necessary as the extension shaft was having a significant effect on the rotor motion. A nonrigid connection between the main shaft and the shaft extension was discovered to be affecting the balance as well. A failure of a ceramic spacer between the REBs put the commissioning procedure on hold until new shaft journals and replacement titanium spacers could be machined. All these factors had to be isolated one at a time in order to locate them. They also provide valuable information for future machine design. After the new journals have been installed, commissioning at higher speeds will continue.

\section{REFERENCES}

K. Choy and J. Halloran, "Application of Hydrostatic SqueezeFilm Dampers," ASME Transactions, vol 25, vol 2, pp 245-251.

E. Gunter, "Influence of Flexibly Mounted Rolling Element Bearings on Rotor Response Part 1 - Linear Analysis," J. Lubrication Technology, January 1970, pp 59-75.

R.N. Headifen, "Rotordynamic Modeling of Flexible Rotor Machines Supported with Hydrostatic Bearings," Ph.D. Dissertation, The University of Texas at Austin, Austin, TX .1991

C. Jackson, "The Practical Vibration Primer," Gulf Publishing Co. Book Division, Houston, TX 1979.

J. Kitzmiller, "Commissioning the Rotor-Bearing Systems in the Balcones 60 Megajoule Modular Homopolar Power Supply at the Center for Electromechanics,"'Master Thesis, The University of Texas at Austin, Austin, TX 1988.

S. Manifold, "TXROTOR, Users Guide," CEM-UT Internal Report, 1989.

J. Vance, "Rotordynamics of Turbomachinery," Texas A\&M University, 1988, John Wiley and Sons, New York, New York.

W.F. Weldon, H.H. Woodson, M.D. Driga, Invention: Compensated Pulsed Alternator, U.S. Patent \# 4,200,831, granted April 29,1980 . 


\section{APPENDIX A}

\section{MAIN DAMPER PARAMETERS}

4 Pocket, Diameter 7.250, Pocket length 1.000, Axial land length 0.750 , Inter Pocket Land length 1.000, Pocket Depth 0.090, Clearance 0.003 , Orifice Diameter 0.050 , Fluid density $0.03 \mathrm{lb} / \mathrm{in} .{ }^{3}$, Fluid Viscosity $0.22 \mathrm{E}-6$ Reyn, Supply Pressure $350 \mathrm{psi}$, Concentric Pressure Ratio 0.186. Maximum endland Reyolds number 28-35

SHAFT EXTENSION DAMPER PARAMETERS

Same design except the diameter was 6.500 


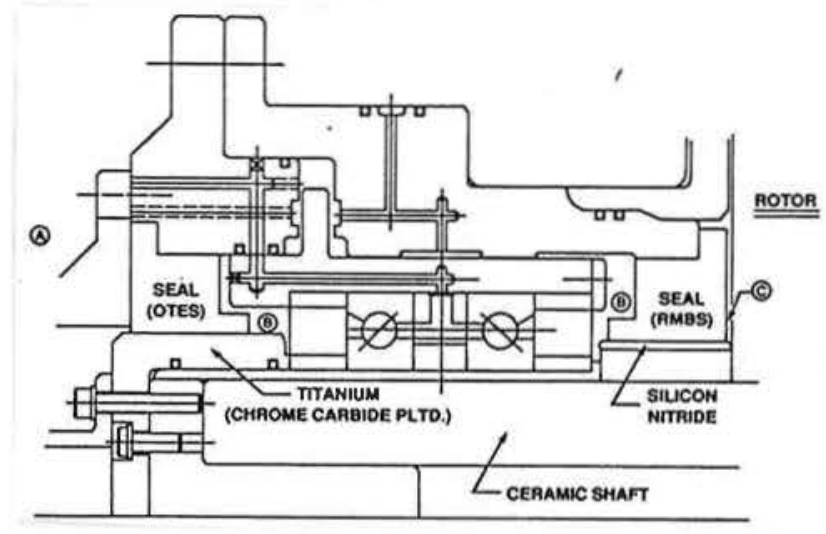

Figure 1 Arrangement of the Damper and REBs. Thrust End Shown

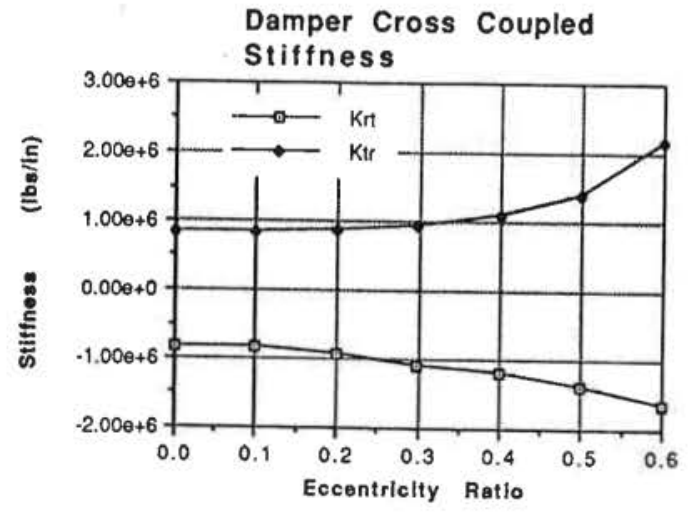

Figure 3 Damper Cross Coupled Stiffness Coefficients

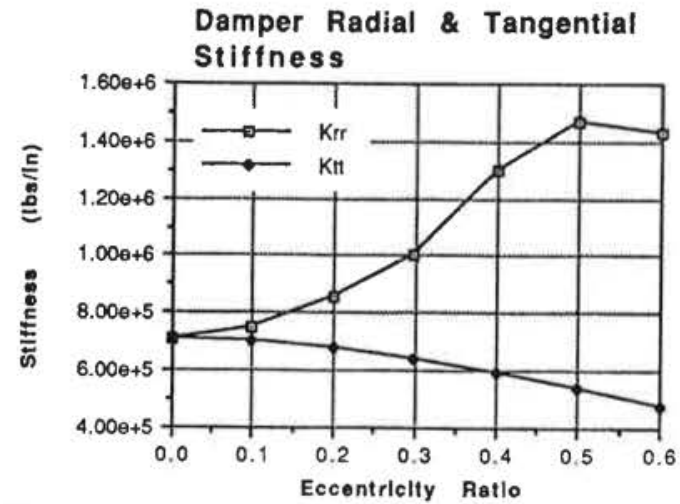

Figure 2 Damper Radial Stiffness Coefficients

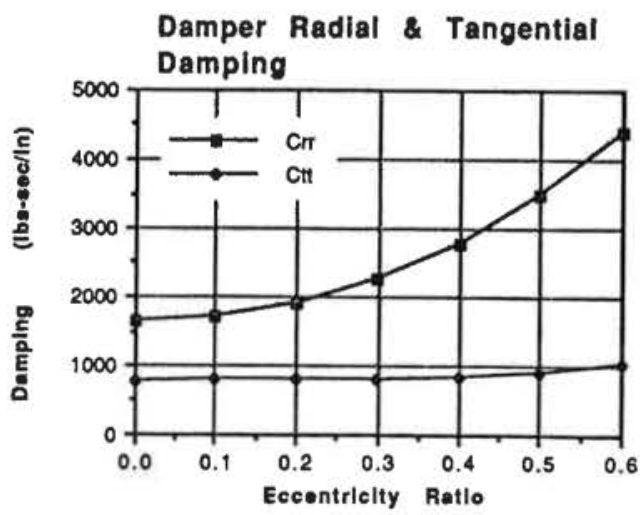

Figure 4 Damper Radial Damping Coefficients 
R O D Y N

WHIRL DRBIT AT BEARINO NO. 1

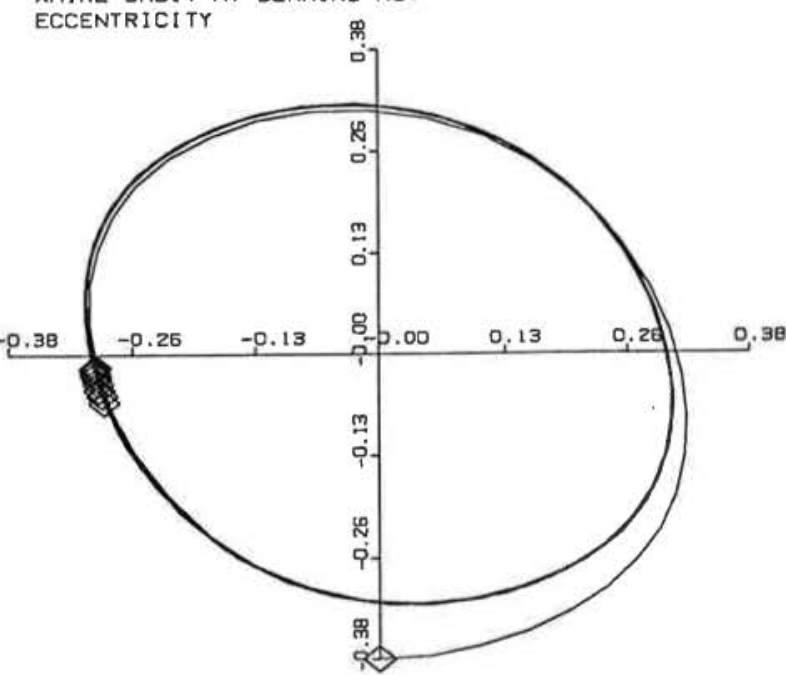

Figure 5 Damper Orbit at 10,000 rpm from Bearing Simulator Program

R O D Y N P L O T WHIRL ORBIT AT BEARING NO. 1

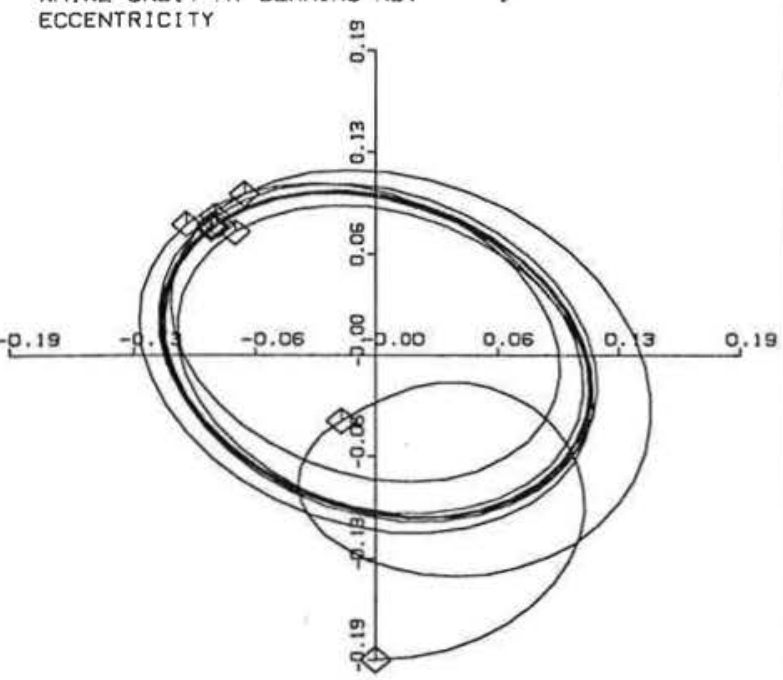

Figure 7 Damper Orbit at 25,000 rpm with Compressibility Included

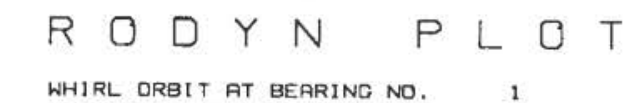

WHIRL ORBIT AT BEARING NO.

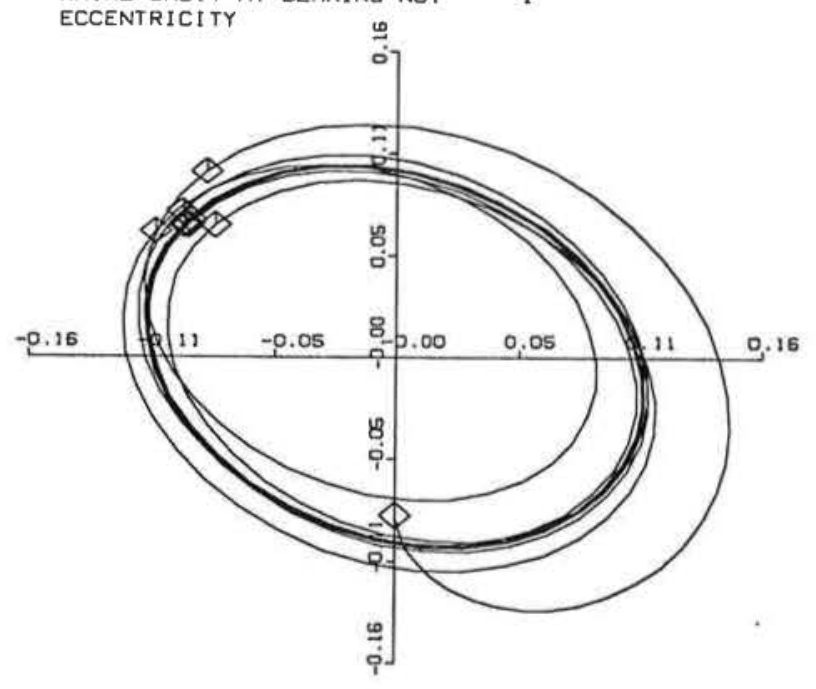

Figure 6 Damper Orbit at $25,000 \mathrm{rpm}$ from Bearing Simulator

R O D Y N P L O T

WHIRL DRBIT RT BEARINO NO. 1

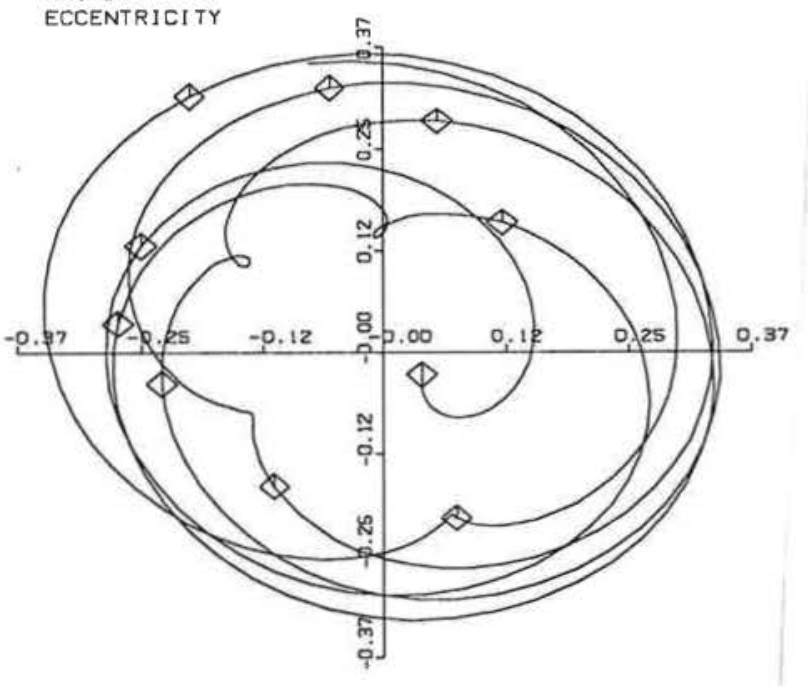

Figure 8 Damper Orbit at 25,000 rpm with Journal Spinning and Whirling 


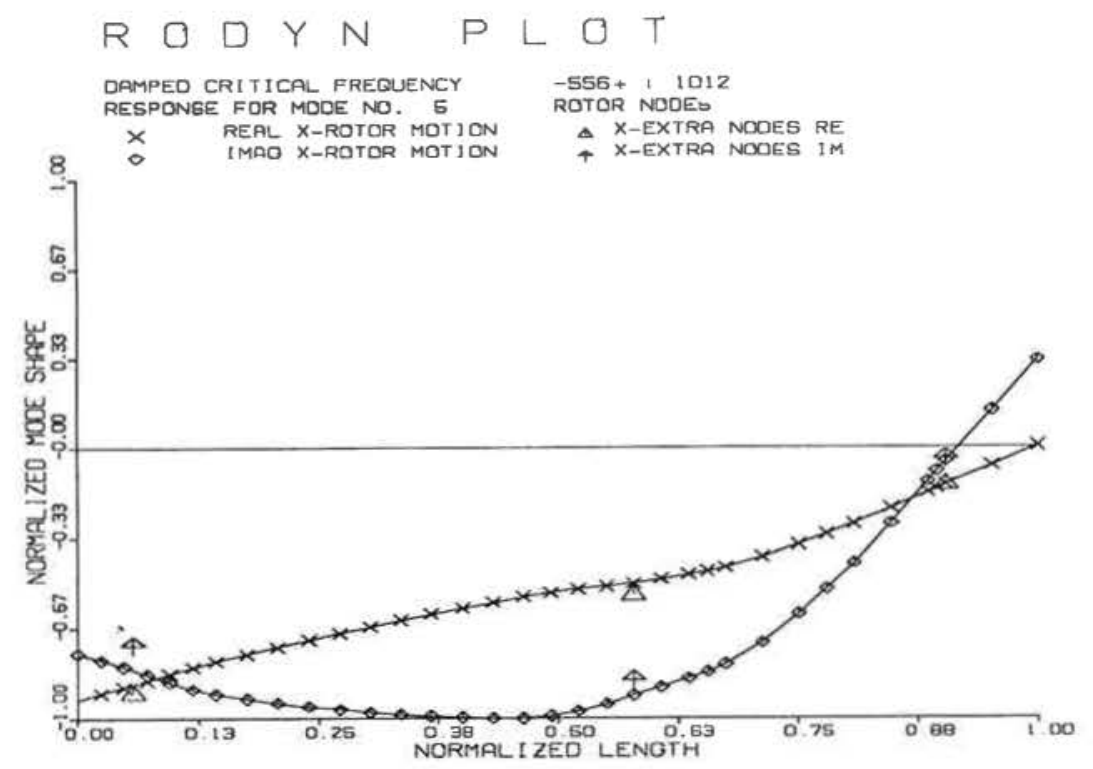

Figure 9a First Eigenvector Mode Shape

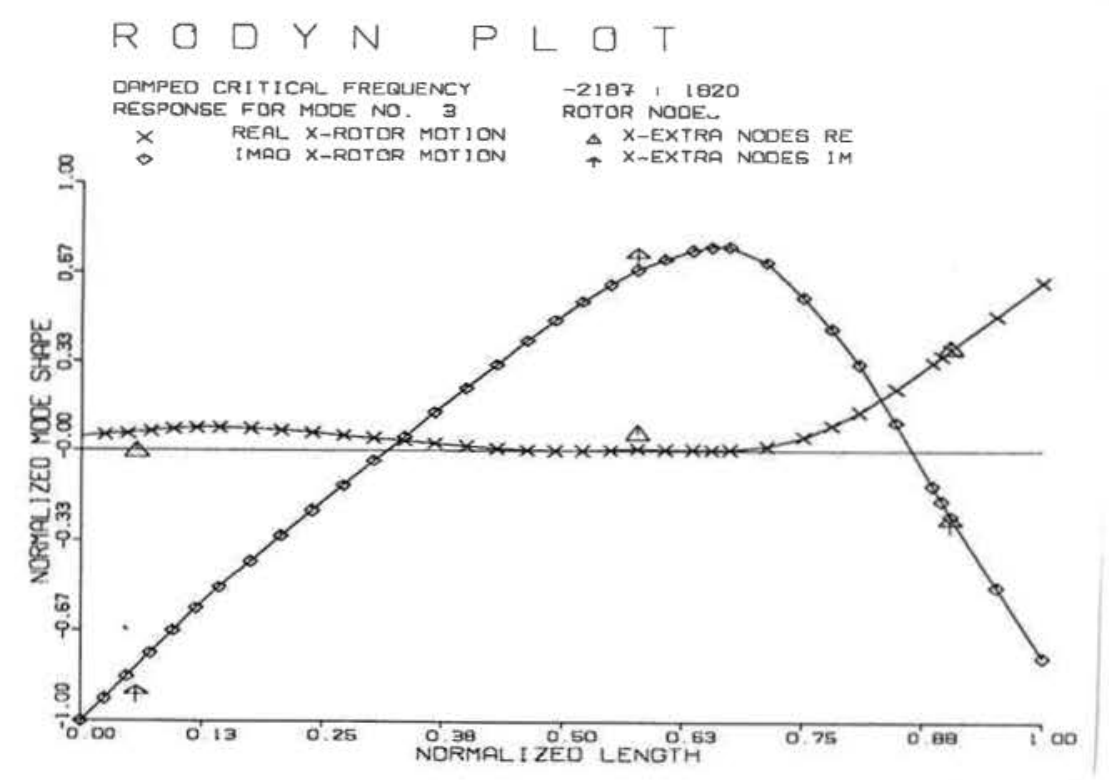

Figure 9b Second Eigenvector Mode Shape 

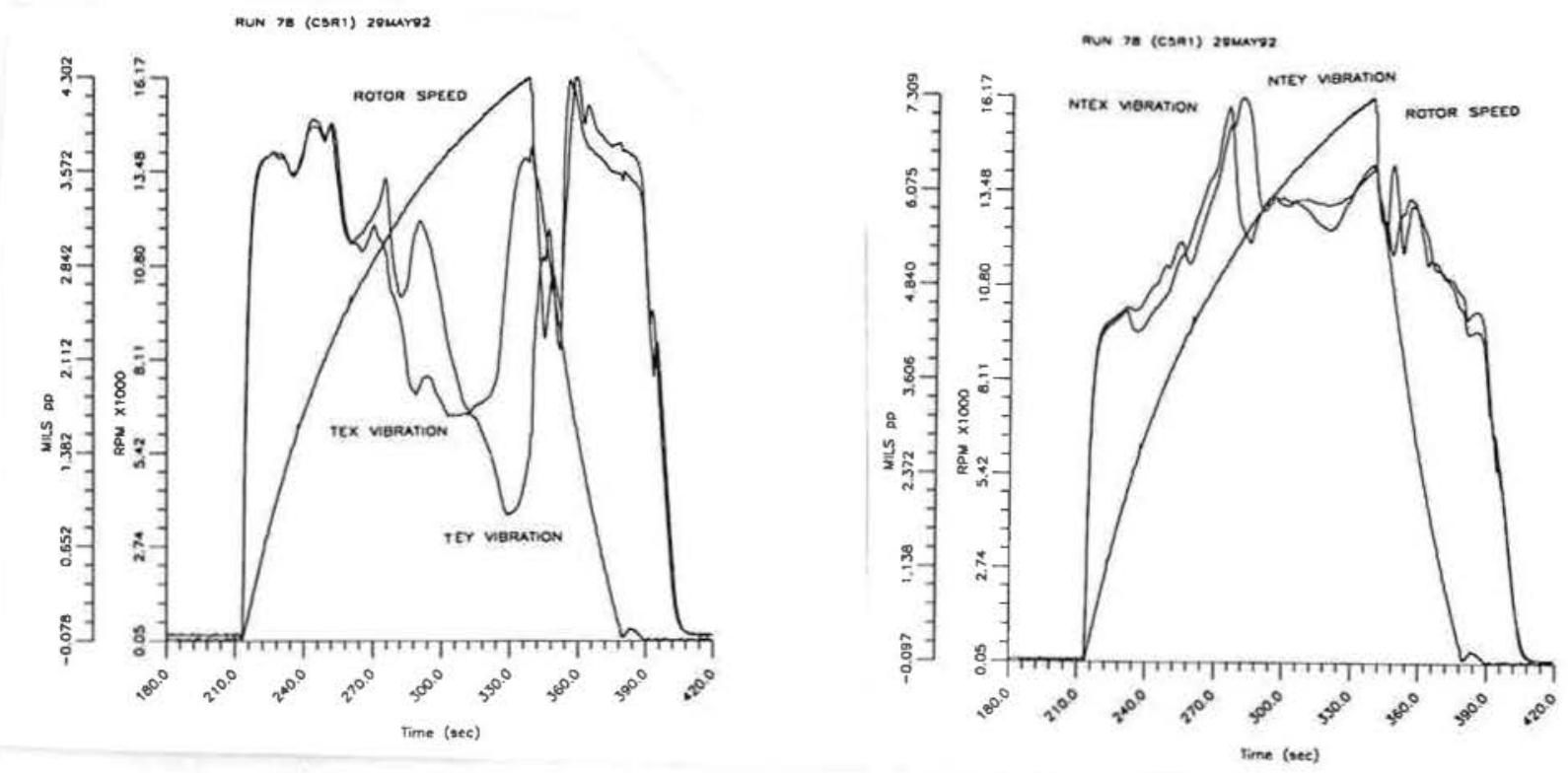

Figure 10a Run \# 78 Vibration at TE

Figure 10b Run \# 78 Vibration at NTE
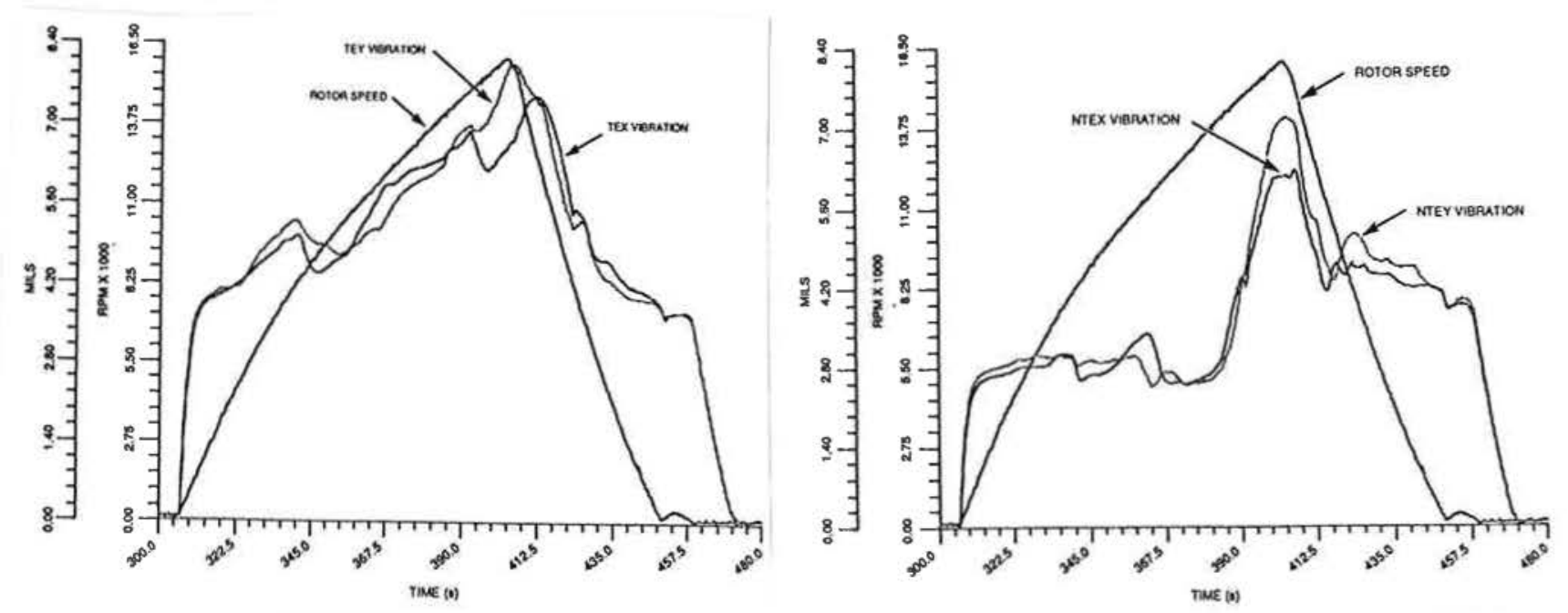

Figure 11a Run \# 85 Vibration at TE

Figure 11b Run \# 85 Vibration at NTE 


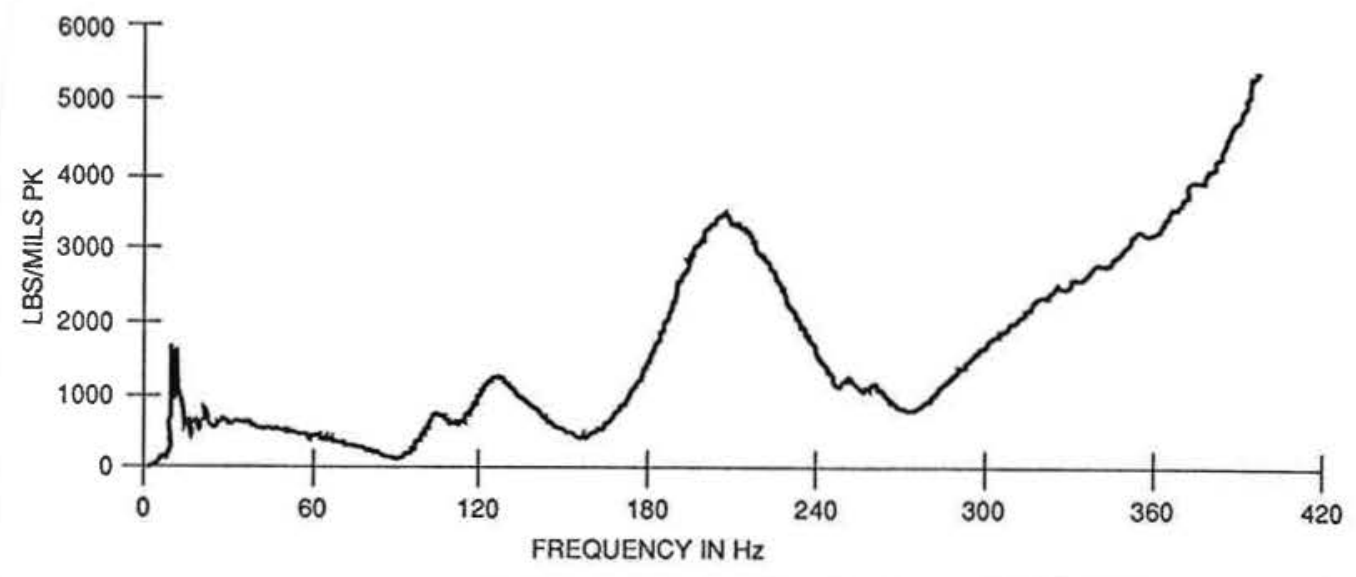

Figure 12 Tie down Skid Dynamic Stiffness

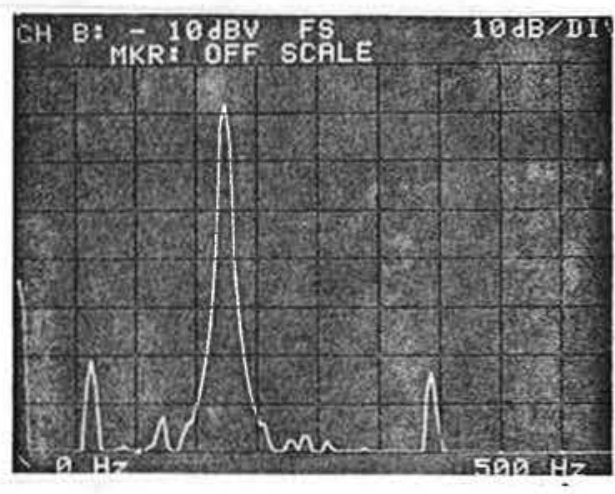

Figure 13a Proximitor Vibration Showing Two Times Operating Speed Vibrationat $10,000 \mathrm{rpm}$

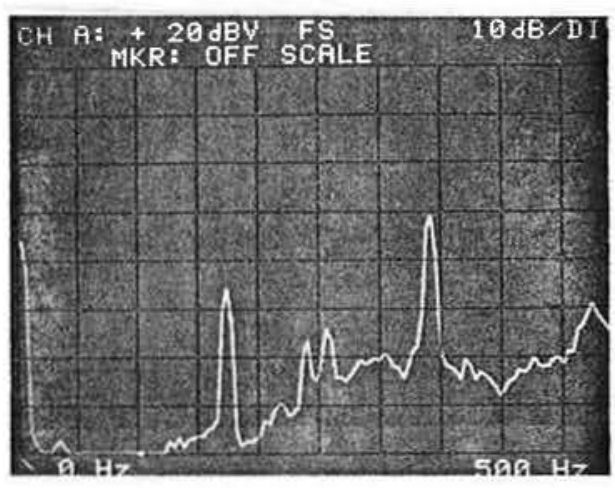

Figure 13b Accelerometer Vibration Showing Two Times operating Speed Vibration at 10,000 rpm 